\title{
Explicando as Diferenças de Pobreza entre Produtores Agrícolas no Brasil: simulações contrafactuais com o censo agropecuário 1995-96
}

\author{
Steven M. Helfand ${ }^{2}$ \\ Ajax Reynaldo Bello Moreira ${ }^{3}$ \\ Adriano Marcos Rodrigues Figueiredo ${ }^{4}$
}

Resumo: O censo agropecuário 1995-96 é utilizado para estudar os fatores responsáveis pelas diferenças na pobreza entre os estabelecimentos agrícolas no Brasil. As diferenças entre as regiões e as seguintes dicotomias são analisadas: proprietários/não proprietários; familiares/não familiares; intensivos em insumos/não intensivos; com/sem máquinas. $\mathrm{O}$ artigo utiliza uma metodologia semiparamétrica. Primeiro, uma função fronteira estocástica de lucro é estimada. Em seguida, simulações não paramétricas contrafactuais são utilizadas para identificar os fatores que explicam as diferenças em pobreza. Os fatores incluem o tamanho da propriedade, o trabalho familiar, a lucratividade e as variáveis utilizadas para explicar a lucratividade no modelo de fronteira estocástica. $\mathrm{O}$ artigo conclui que a falta de terra e os baixos níveis de produtividade são importantes motivos para a pobreza entre produtores agrícolas. É improvável que qualquer um deles isoladamente possa solucionar o problema da pobreza. As diferenças em "eficiência" - capturadas pelo termo de erro na função fronteira de lucro - são importantes para explicar as diferenças entre os pobres e os não pobres, mas não para as demais dicotomias estudadas. Isto sugere que os fatores

1 O artigo se baseia em pesquisa financiada, em parte, pela United States Agency for International Development (USAID) através do programa Basis/CRSP. Essas instituições não têm qualquer responsabilidade sobre as opiniões e conclusões do trabalho. Os autores agradecem comentários e sugestões recebidos de participantes de seminários realizados no Ipea, e em particular a Eustáquio Reis, em conferências do Basis, e de dois pareceristas anônimos da revista.

2 University of California, Riverside (UCR), USA. E-mail: steven.helfand@ucr.edu

3 Instituto de Pesquisa Econômica Aplicada (IPEA), Rio de Janeiro (RJ). E-mail: ajaxmoreira@gmail.com

4 Universidade Federal de Mato Grosso (UFMT), Cuiabá (MT).E-mail: adriano@ufmt.br 
Explicando as Diferenças de Pobreza entre Produtores Agrícolas no Brasil: simulações contrafactuais com o censo agropecuário 1995-96

não observáveis - como restrições ou falhas de mercado - são importantes para explicar a pobreza entre produtores agrícolas no Brasil.

Palavras-chave: Pobreza, agricultura, Brasil.

\begin{abstract}
The 1995-96 agricultural census is used to explore factors that account for differences in poverty among agricultural establishments in Brazil. Differences across regions and the following dichotomies are analyzed: owners/non-owners, family/nonfamily, input intensive/non-intensive, with machines/without machines. The paper uses a semi-parametric methodology. First, a stochastic frontier profit function is estimated. Then, non-parametric counterfactual simulations are used to identify factors which explain differences in poverty. Factors include farm size, family labor, profitability and the variables used to explain profitability in the stochastic frontier model. The paper concludes that lack of land and low levels of productivity are both important reasons for poverty among agricultural producers. It is unlikely that either one alone could solve the poverty problem. Differences in "efficiency" - captured by the error term in the frontier profit function - are important to explain differences between the poor and non-poor, but not for any of the other dichotomies studied. This suggests that unobservable factors - such as restrictions or market failures - are important to explain poverty among agricultural producers in Brazil.
\end{abstract}

Key-words: Poverty, agriculture, Brazil.

Classificação JEL: O13, I32, Q12.

\title{
1. Introdução
}

A pobreza rural, a pobreza entre pessoas que trabalham na agricultura, e a pobreza entre os produtores agrícolas são correlacionadas no espaço. Mas os três conceitos envolvem populações diferentes. Uma parte dos residentes rurais tem trabalhos que não têm relação com a agricultura. Esse grupo não é o enfoque deste trabalho. Outro grupo de residentes rurais não tem acesso à terra e sobrevivem principalmente com renda de salários, ou agrícolas ou não agrícolas. Este grupo também não é o enfoque deste trabalho. O trabalho focaliza exclusivamente os estabelecimentos agropecuários segundo a definição do Censo Agropecuário de 1995-96. Os estabelecimentos - chamados de "produtores" neste artigo - produzem lavouras, animais e outros produtos, podem ser familiares ou não, e incluem proprietários e não proprietários ${ }^{5}$.

5 O Censo Agropecuário 1995-96 (IBGE, 1998, p. 29) define o estabelecimento agropecuário como "todo terreno de área contínua, independente do tamanho ou situação (urbana ou rural), formado de uma ou mais parcelas, subordinado a um único 
A pobreza entre os produtores agrícolas pode ter origens diferentes. Alguns produtores podem gerar renda insuficiente devido à baixa produtividade. Outros produtores, apesar de muito produtivos, podem ter terra insuficiente, ou uma família muito grande, para poder gerar um nível de renda per capita que supere a linha de pobreza. Também são variadas as razões pelas quais alguns produtores são mais produtivos do que outros, incluindo diferenças de tecnologia, capital disponível no estabelecimento, capital humano e experiência do produtor e qualidade da infraestrutura local.

O objetivo deste trabalho é analisar as diferenças na pobreza entre produtores agrícolas no Brasil. Especificamente, objetiva-se entender os fatores que: 1) explicam as diferenças de pobreza entre as regióes brasileiras; 2) determinam a pobreza dentro de cada macrorregião; e 3) explicam as diferenças na pobreza entre diferentes clivagens dos produtores - como proprietários e não proprietários ou produtores familiares e não familiares - em uma dada região. Em todos os casos, uma pergunta chave é a relação entre a pobreza, o tamanho do estabelecimento e a produtividade.

A metodologia utilizada neste artigo para responder a estas perguntas baseia-se na abordagem de simulações contrafactuais de Juhn, Murphy e Pierce (JMP, 1993). Quando o interesse é na diferença nas médias de dois grupos, a decomposição de Oaxaca-Blinder (OAXACA, 1973; BLINDER, 1973) é o exercício contrafactual que pode ser utilizado para avaliar o efeito da diferença entre as médias das variáveis determinantes sobre a diferença entre as médias do resultado. Como esta decomposição não funciona para o estudo da pobreza que é uma função da distribuição da renda, e não só da renda média - utiliza-se uma extensão da decomposição de Oaxaca-Blinder proposta por JMP. A extensão considera o efeito sobre a diferença entre as distribuições da renda devido à diferença entre as distribuições dos determinantes. As simulações contrafactuais são utilizadas para identificar os fatores que determinam as diferenças de pobreza entre as regiões, dentro de cada macrorregião, e entre grupos em uma dada região. Os fatores explanatórios analisados incluem tamanho da propriedade, uso de trabalho familiar, lucratividade e grupos de variáveis utilizadas para explicar a lucratividade num modelo de fronteira estocástica.

Para estudar a pobreza entre os produtores, os microdados do Censo Agropecuário de 1995-96 numa extensão ao trabalho de Moreira, Helfand e

produtor, onde se processasse uma exploração agropecuária, ou seja: o cultivo do solo com culturas permanentes e temporárias, inclusive hortaliças e flores; a criação, recriação ou engorda de animais de grande e médio porte; a criação de pequenos animais; a silvicultura ou o reflorestamento; e a extração de produtos vegetais".

6 Os autores agradecem ao IBGE por permitir que processássemos os microdados do censo. 
Figueiredo $(2007)^{7}$ foram utilizados. O censo é uma fonte de informações muito rica para se estudar as rendas agrícolas dos produtores porque tem informações sobre produção, uso de insumos e práticas agrícolas. Por outro lado, não é apropriada para se estudar a pobreza de forma mais ampla, por exemplo, entre todos os residentes de áreas rurais, porque não tem informações sobre rendas não agrícolas e transferências. Estas questões de unidade de análise e definição de renda são discutidas nas próximas seções do artigo.

Apesar de serem dados dos anos 90, muito pode ser apreendido do Censo Agropecuário 1995-96. Primeiro, o fenômeno aqui estudado, relacionado à distribuição da propriedade da terra no Brasil e à produtividade, muda lentamente e não se devem esperar resultados dramaticamente diferentes com dados mais recentes. Segundo, embora o Censo Agropecuário 2006 tenha sido divulgado recentemente, transcorrerão alguns anos até a análise aqui conduzida poder ser reproduzida. Planeja-se realizar isto no futuro, de modo a estudar mudanças nos determinantes da pobreza. Finalmente, a metodologia de simulação utilizada neste artigo é inovadora no contexto da agricultura brasileira, visto que provê uma valiosa ferramenta para estudo das fontes de pobreza, e pode ser aplicada a outras bases de microdados no Brasil.

$\mathrm{O}$ artigo está organizado da seguinte forma: a seguir, tem-se uma breve revisão de literatura sobre o uso de distintas bases de dados para estudar a pobreza no Brasil. Na terceira seção, serão apresentados dados que caracterizam a pobreza de produtores agrícolas e motivam o trabalho. Mostra-se que, apesar de definições e fontes de dados diferentes, existe uma correlação elevada entre a medida de pobreza aqui calculada com o Censo Agropecuário e as medidas domiciliares de pobreza calculadas com o Censo Demográfico. Também se mostram dados descritivos, os quais sugerem que, isoladamente, nem a redistribuição de terra nem o aumento de produtividade seriam capazes de resolver o problema de pobreza na agricultura brasileira. A metodologia está apresentada na quarta seção do artigo. Primeiro, estima-se um modelo de fronteira estocástica de lucro. Os resultados da estimação são utilizados para realizar exercícios contrafactuais que explicitam as fontes da pobreza. A quinta seção discute os resultados, e a sexta seção traz as conclusões do artigo.

\section{O que o Censo Agropecuário pode adicionar aos estudos de pobreza?}

A maioria dos estudos de pobreza no Brasil utilizam dados da Pesquisa Nacional por Amostra de Domicílios (PNAD). A PNAD é uma pesquisa

7 Em Moreira, Helfand e Figueiredo (2007), o foco é produtividade. No presente trabalho, o foco é a pobreza, e utiliza a base de dados de produtividade produzida em Moreira, Helfand e Figueiredo (2007). 
domiciliar realizada anualmente - com a exceção dos anos censitários, ou por razões excepcionais - pelo IBGE há cerca de quarenta anos. Ela consiste numa valiosa fonte de informações sobre a renda, o emprego, e as características domiciliares e individuais necessárias para se estudar a pobreza. Exemplos do uso da PNAD incluem estudos que buscam explicar a evolução temporal da pobreza (FERREIRA et al., 2010), construir indicadores multidimensionais da pobreza (KAGEYAMA e HOFFMANN, 2006), decompor a evolução temporal da pobreza rural em parcelas de crescimento e distribuição (HELFAND et al., 2009), calcular a elasticidade de pobreza em relação à renda média e à desigualdade (HOFFMANN, 2005), e estudar alternativas de mitigação da pobreza (ROCHA, 2007). Alguns autores têm utilizado a PNAD para estudar a pobreza entre indivíduos que trabalham na agricultura (CORREAA, 1998). Muitos outros têm utilizado a PNAD como parte do Projeto Rurbano (CAMPANHOLA e GRAZIANO DA SILVA, 2000), para se estudar a pluriatividade e a importância do emprego e da renda não agrícolas nas áreas rurais.

A PNAD tem limitações ao estudo da pobreza rural, e estas são mais severas quando a população de interesse envolve produtores agrícolas, comparativamente aos domicílios rurais. Como descrito por Ferreira e Lanjouw (2001), a pergunta sobre rendas não considera: a) a renda não monetária, b) uma distinção clara entre as rendas bruta e líquida para os conta própria; c) as rendas sazonais de maneira adequada, comuns na agricultura; ou d) o autoconsumo de produtos agrícolas dos produtores. Estas limitações na forma como a renda é mensurada pela PNAD são mais problemáticas para os produtores pequenos que trabalham por conta própria - um grupo com altas taxas de pobreza pois suas rendas são sazonais, nem sempre monetárias, e eles frequentemente consomem uma parcela significativa do que produzem.

Alguns autores têm utilizado o Censo Demográfico ao invés da PNAD para estudar rendimentos no meio rural (NEY e HOFFMANN, 2009). Enquanto a PNAD somente é representativa estatisticamente em nível estadual para o Brasil rural, o Censo tem a vantagem de o ser em nível municipal. A definição de renda, entretanto, é muito similar à utilizada pela PNAD e, portanto, ambas sofrem as mesmas limitações.

Na tentativa de superar as limitações da PNAD no estudo da pobreza, especialmente em áreas rurais, alguns autores têm utilizado a Pesquisa de Orçamentos Familiares (POF). Por exemplo, Figueiredo et al. (2007) utilizaram a POF para estudar a pobreza rural e examinar as diferenças entre as medidas de pobreza baseadas na renda (como as na PNAD) versus consumo. Eles encontraram que as medidas baseadas na renda superestimam a pobreza entre 12 e 17 pontos percentuais ao nível de macrorregião no Brasil.

O World Bank (2006) e Silveira et al. (2007) também utilizaram a POF para medir a pobreza baseada no consumo. Embora a POF tenha certas vantagens para o estudo da pobreza rural, ela também tem limitações. Os levantamentos da 
POF conduzidos em 1987-88 e 1995-96 foram restritos às áreas metropolitanas e a algumas grandes cidades. Portanto, elas não podem ser utilizadas para o estudo da pobreza rural. A POF de 2002-03 cobriu todo o Brasil e foi estatisticamente representativa em nível macrorregional para as áreas rurais. Por este motivo, naquele ano, a POF é uma excelente fonte para a mensuração da pobreza rural. Ela não oferece, entretanto, informações sobre o uso ou a propriedade da terra, nem apresenta qualquer informação sobre os insumos utilizados na produção agrícola. Desta forma, ela não pode ser utilizada para estudar como diferentes quantidades de terra, níveis de produtividade, ou decisões de uso de fatores afetam a renda e a pobreza entre produtores agrícolas.

Acredita-se que o Censo Agropecuário oferece uma alternativa promissora para o estudo da pobreza entre produtores agrícolas no Brasil. O Censo Agropecuário tem sido utilizado frequentemente para estudar a produtividade agrícola (GASQUES e CONCEIÇÃO, 2000). Também tem sido utilizado para estudar a agricultura familiar (GUANZIROLI et al., 2001). Até onde se sabe, com exceção de Helfand (2004), o Censo Agropecuário não tem sido utilizado para estudar a pobreza no Brasil. Consideradas as limitações das outras bases de dados, e o crescente interesse que a agricultura tem recebido recentemente como potencial meio de mitigação da pobreza dos produtores agrícolas ${ }^{8}$, o momento é oportuno para explorar o potencial do Censo Agropecuário para se compreender as diferenças da pobreza entre produtores agrícolas.

\section{Motivação e estatísticas descritivas}

O conceito de pobreza que se adota neste trabalho refere-se à renda agrícola insuficiente por membro da família ocupado no estabelecimento. O conceito só é relevante para produtores agrícolas e só contempla a renda oriunda da agricultura. Para lembrar o leitor que o conceito de pobreza define-se somente com renda agrícola, frequentemente o termo "pobreza ${ }_{\mathrm{RA}}$ " será utilizado.

Esta medida tem algumas diferenças importantes com relação às medidas de pobreza feitas com pesquisas domiciliares, como a PNAD ou o Censo Demográfico. Por um lado, o conceito aqui utilizado subestima a renda total da família do produtor porque ignora as demais fontes de renda - como transferências e renda do trabalho fora do estabelecimento. Em compensação, mede a renda agrícola melhor do que a PNAD ou o Censo Demográfico porque capta a parcela da produção agrícola usada para subsistência. Por outro lado,

8 A contribuição da agricultura e da terra para reduzir a pobreza foi abordada recentemente por Buainain e Neder (2009), World Bank (2008), Bresciani e Valdés (2007), Finan et al. (2005) e Janvry e Sadoulet (2000). 
enquanto as pesquisas domiciliares captam o tamanho efetivo da família, o Censo Agropecuário só capta os membros da família ocupados no estabelecimento.

Estas diferenças sugerem cuidado no uso do nosso conceito de pobreza. Só é apropriado para estudar questões de produção e renda estritamente agrícolas, e o potencial da agricultura, por si só, de gerar renda suficiente para tirar as pessoas ocupadas da família da pobreza. Apesar das diferenças, os resultados a seguir mostram que a incidência de pobreza medida com este conceito está altamente correlacionada com o conceito domiciliar de pobreza rural.

A renda por membro ocupado no estabelecimento é medida com o valor da produção líquido dos gastos correntes dividido por um índice da quantidade de pessoas ocupadas da família ${ }^{9}$. A incidência de pobreza é medida pela proporção dos estabelecimentos em que a renda por membro da família ocupado no estabelecimento é inferior a uma linha de pobreza comum para todas as regiões. Foram utilizadas duas linhas de pobreza equivalentes a um quarto e à metade do salário mínimo de agosto de 2000, deflacionadas para dezembro de 1995. O salário mínimo de agosto de 2000 era R\$ 151/mês. Estas linhas são iguais às utilizadas em PNUD, IPEA, Fundação João Pinheiro (2003) e Helfand e Levine (2006) e facilita comparações. Resultou em classificar como extremamente pobres os estabelecimentos com renda per capita menor que R\$350/ano, e pobres os com renda per capita menor que $\mathrm{R} \$$ 700/ano em 1995-96.

A Figura 1 mostra a correlação municipal entre os dois conceitos de pobreza: a dos produtores agrícolas, medida com o Censo Agropecuário de 1995-96; e a rural, medida com o Censo Demográfico de $2000^{10}$. A primeira medida de pobreza foi definida nos parágrafos anteriores, e a segunda usa o conceito usual de pobreza em base da renda monetária domiciliar per capita (HELFAND e LEVINE, 2006). A Figura 1 revela uma correlação muito alta entre as duas medidas de pobreza. Isso reflete a alta proporção de famílias rurais que têm renda agrícola e a similaridade dos conceitos. De fato, a correlação municipal entre a medida de pobreza dos produtores em 1995-96 e a pobreza rural no ano 2000 era 0,80 .

9 Com o propósito de aproximar-se ao trabalho efetivo no estabelecimento, este índice pondera as mulheres em relação aos homens pelo número médio de horas trabalhadas de acordo com a PNAD 1995 ao nível de macrorregião. Os pesos maiores para as mulheres foram no Sul e no Nordeste, onde chegaram a 0,60. Nas outras regiões, ficaram em torno de 0,50 . O pessoal ocupado da família com idade inferior a 14 anos recebeu peso equivalente à metade de um adulto masculino. Foram feitos vários testes de robustez, como, por exemplo, usar pesos iguais a um para as mulheres, e os resultados qualitativos não foram afetados.

10 Como o número de municípios variou na década de 90, os resultados foram apurados em áreas mínimas comparáveis, que são unidades espaciais de 1991 e que são invariantes no período. 
Explicando as Diferenças de Pobreza entre Produtores Agrícolas no Brasil: simulações contrafactuais com o censo agropecuário 1995-96

Figura 1. Incidência de pobreza segundo o Censo Demográfico de 2000 e o Censo Agropecuário de 1995-96

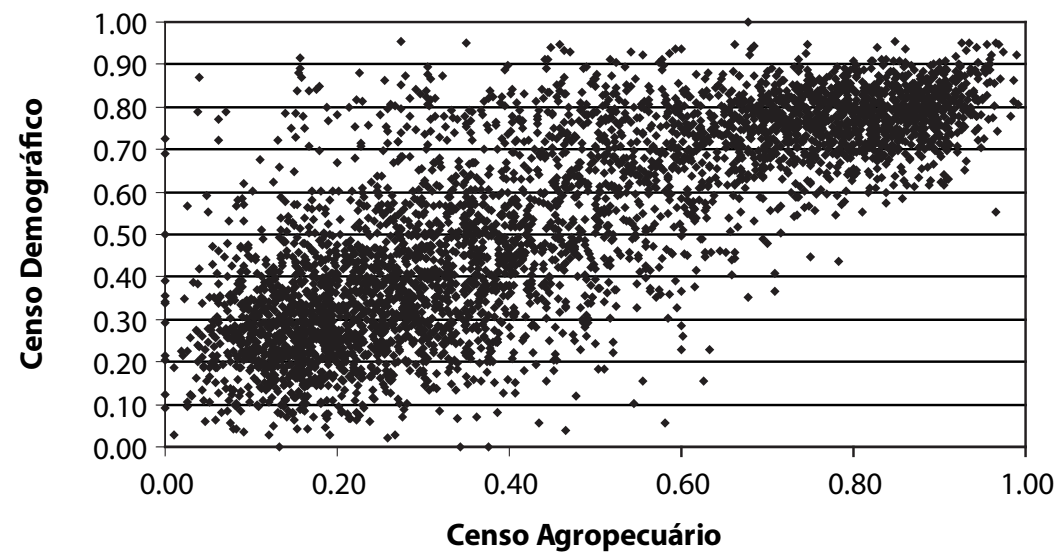

Fonte: IBGE, Censo Agropecuário 1995-96 e Censo Demográfico 2000, dados trabalhados.

Tabela 1. Incidência de pobreza segundo os censos Demográfico (1991 e 2000) e Agropecuário 1995-96 - Brasil e macrorregiões

\begin{tabular}{ccccccc}
\hline \multirow{2}{*}{ Região } & \multicolumn{3}{c}{ Pobreza (1/2 SM) } & \multicolumn{3}{c}{ Extrema Pobreza (1/4 SM) } \\
\cline { 2 - 7 } & $D-1991$ & $D-2000$ & $A-1995$ & $D-1991$ & $D-2000$ & $A-1995$ \\
\hline Brasil & 0,72 & 0,61 & 0,53 & 0,45 & 0,36 & 0,36 \\
Norte & 0,69 & 0,70 & 0,48 & 0,40 & 0,44 & 0,26 \\
Nordeste & 0,85 & 0,77 & 0,76 & 0,60 & 0,51 & 0,57 \\
Sudeste & 0,61 & 0,42 & 0,32 & 0,32 & 0,19 & 0,18 \\
Sul & 0,56 & 0,35 & 0,22 & 0,28 & 0,15 & 0,10 \\
Centro-Oeste & 0,57 & 0,43 & 0,25 & 0,27 & 0,19 & 0,13 \\
\hline
\end{tabular}

* SM - salário mínimo oficial; D - dados dos Censos Demográficos 1991 ou 2000 e A do Censo Agropecuário 1995-96.

Fonte: Helfand e Levine (2006) e dados da pesquisa.

A Tabela 1 compara a incidência de pobreza do produtor agrícola com a incidência de pobreza rural no Brasil e em suas macrorregiões. Como os conceitos são diferentes, não deve surpreender que os níveis sejam diferentes. Mesmo assim, a tabela mostra que o padrão entre regiões é parecido com os dois conceitos e duas fontes de dados. O Nordeste tem a maior incidência de pobreza rural e do produtor, 0,77 , segundo o Censo Demográfico em 2000 e 0,76 segundo o Censo Agropecuário de 1995-96. De acordo com os dois conceitos, a região Norte é a que tem a segunda maior incidência de pobreza, e a região Sul, a com a menor incidência. $\mathrm{O}$ mesmo padrão entre regiões é observado quando um quarto do salário mínimo é utilizado como linha de extrema pobreza. As altas 
correlações entre as medidas de pobreza baseadas nos censos Agropecuário e Demográfico, observadas na Figura 1 e Tabela 1, oferecem certo grau de validade à abordagem adotada neste artigo para o estudo da pobreza.

O tamanho dos estabelecimentos e a produtividade são determinantes chaves da pobreza entre os produtores agrícolas. Desta forma, faz-se necessário contextualizar a pobreza dos produtores em conjunto a esses dois elementos. As Figuras 2 e 3, para as regiões Sul e Nordeste, apresentam a porcentagem de produtores pobres por classe de tamanho do estabelecimento e décimo de Produtividade Total de Fatores (PTF). A medida de PTF foi estimada em Moreira et al. (2007), usando o Censo Agropecuário 1995-96. As figuras mostram a relação entre o aumento da PTF e a redução da pobreza por classe de tamanho do estabelecimento. Desta forma, as curvas medem o grau de substituição entre terra e PTF na determinação de pobreza. A interseção das linhas horizontais de igual pobreza com as curvas mostram o quanto de terra pode ser substituída por produtividade, e como esta substituição muda com as regiões.

Figura 2. Porcentagem de pobres por classe de tamanho (em hectares) e décimo de produtividade total de fatores (PTF): Sul do Brasil

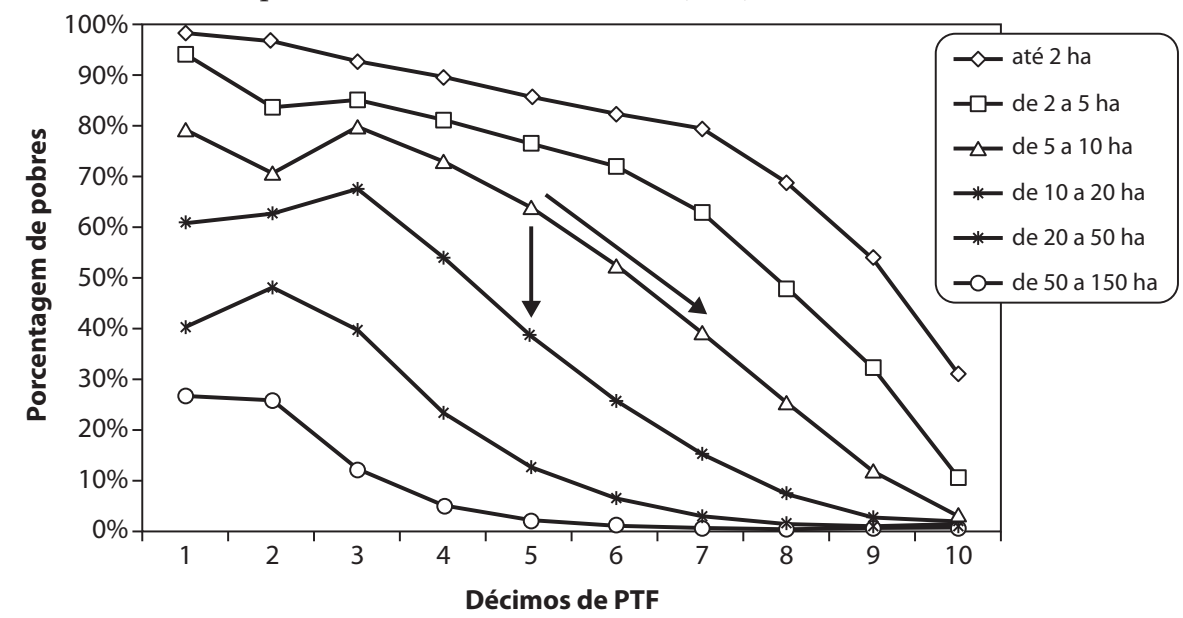

Fonte: IBGE, Censo Agropecuário 1995-96, dados trabalhados em Moreira et al.(2007).

Por exemplo, no Sul (Figura 2), mais de 60\% dos estabelecimentos com 5-10 hectares são pobres no quinto décimo de PTF. Se o tamanho desses estabelecimentos fosse aumentado para 10-20 hectares, poder-se-ia reduzir a incidência de pobreza para 40\%, mantendo o décimo de PTF constante. Também poderia reduzir a pobreza desses estabelecimentos para $40 \%$, mantendo-se o tamanho constante, se aumentasse a PTF para o sétimo décimo. 
Para reduzir a incidência de pobreza no Nordeste para $40 \%$, por outro lado, seria necessário ter 50-150 hectares no sexto décimo de PTF, 20-50 hectares no oitavo décimo de PTF ou 5-10 hectares no último décimo de PTF (Figura 3).

Figura 3. Porcentagem de pobres por classe de tamanho (em hectares) e décimo de produtividade total de fatores (PTF): Nordeste do Brasil

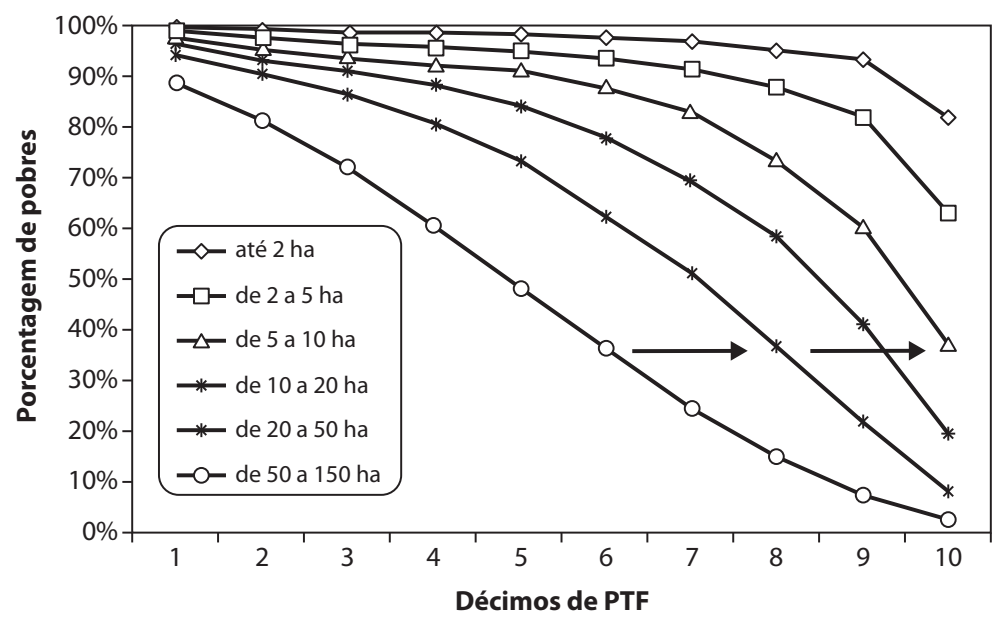

Fonte: IBGE, Censo Agropecuário 1995-96, dados trabalhados em Moreira et al. (2007).

A mesma análise para o Centro-Oeste revela cerca de $60 \%$ dos estabelecimentos pobres entre 5 e 10 hectares para o quinto décimo de PTF. Para alcançar uma renda tal que a pobreza ficasse em $40 \%$, com a mesma área, a produtividade teria que aumentar para o nono décimo, ou a área deveria, para a mesma PTF, aumentar para 20-50 hectares. Em todas as regiões, fica evidente que tanto terra quanto produtividade podem ajudar a reduzir a pobreza, mas dificilmente poderiam resolver o problema da pobreza sem utilizar as duas estratégias juntas. Examinase esta questão em mais detalhe no restante do artigo.

\section{Metodologia}

Nesta seção, definem-se as variáveis e os métodos utilizados na análise. $\mathrm{Na}$ seção 4.1, mostra-se que a renda per capita é uma função do lucro por hectare do estabelecimento e de outras variáveis. Um modelo de fronteira estocástica é então usado para explicar o lucro por hectare do estabelecimento. O modelo permite estimar a relação entre o lucro e grupos de variáveis que serão usadas na análise de pobreza. Algumas dessas variáveis são observadas, como o uso de insumos, o tamanho do estabelecimento e a distância aos mercados. As variáveis 
não observadas, como as habilidades do produtor, são capturadas no termo de eficiência do modelo de fronteira estocástica.

A metodologia de simulação contrafactual é apresentada na seção 4.2. Em contraste à tradicional análise Oaxaca-Blinder (OAXACA, 1973; BLINDER, 1973), que procura explicar diferenças entre as médias de dois grupos, a abordagem aqui usada foca nas diferenças entre as distribuições das variáveis. Isto é importante, pois a pobreza depende não apenas da renda média, mas também da distribuição da renda.

Utiliza-se a metodologia contrafactual para três tipos de exercícios. As simulações identificam a importância relativa dos fatores que: 1) influenciam as diferenças na pobreza entre as regiões brasileiras; 2 ) determinam a pobreza dentro de cada macrorregião; e 3) explicam as diferenças na pobreza entre grupos dentro de uma dada região. Os fatores analisados incluem o tamanho do estabelecimento, o uso de trabalho familiar, lucratividade, e o grupo de variáveis usadas para explicar a lucratividade no modelo de fronteira estocástica. A análise de pobreza entre grupos foca em: a) proprietários versus não proprietários; b) estabelecimentos que usam trabalho contratado versus aqueles que usam apenas trabalho familiar; c) estabelecimentos com versus sem máquinas; ed) estabelecimentos que usam insumos adquiridos mais intensamente que aqueles que os usam menos intensamente.

\subsection{Renda per capita, lucro, e o modelo de fronteira estocástica}

A renda per capita do produtor agrícola $(\pi)$ refere-se ao valor da produção $\left(p^{\prime} q\right)^{11}$ líquido dos custos variáveis $\left(\mathrm{w}^{\prime} \mathrm{x}\right)^{12}$, dividido pelo número de membros da família ocupados no estabelecimento $(\mathrm{N})^{13}$, conforme a equação (1). Esta equação pode ser reparametrizada como (2), onde o valor líquido da produção é dividido pela área do estabelecimento $(\mathrm{T})^{14}$, explicitando a lucratividade, ou lucro por hectare $(\mathrm{L})$ :

11 Esta variável é a soma do valor da produção de 17 tipos de animais, 13 produtos de lavoura permanente, inclusive reflorestamento, e 20 produtos de lavoura temporária. Inclui todos os produtos identificados no Censo Agropecuário, exceto os da indústria rural e das atividades de extração vegetal para manter a consistência com a definição da área utilizada.

12 Ignorando-se a depreciação do capital, que não é disponível no Censo Agropecuário, esta medida de renda é uma medida de lucro de curto prazo.

13 O número de membros da família ocupados no estabelecimento é o índice que pondera homens, mulheres e crianças, segundo a nota de rodapé 5.

14 O tamanho do estabelecimento foi medido como um quantum de terra (T), em que as áreas de pastagens e de lavouras foram ponderadas com os respectivos preços médios estaduais (que revela, em parte, a qualidade do solo). Os preços da terra são da Fundação Getúlio Vargas (FGV). A variável T inclui todos os tipos de uso do solo, exceto as áreas inaproveitáveis e de floresta natural. 
402 - Explicando as Diferenças de Pobreza entre Produtores Agrícolas no Brasil: simulações contrafactuais com o censo agropecuário 1995-96

$$
\begin{aligned}
& \pi=\frac{\left(p^{\prime} q-w^{\prime} x\right)}{N} \\
& \pi=\frac{\left(p^{\prime} q-w^{\prime} x\right)}{T} \frac{T}{N}=L \frac{T}{N}
\end{aligned}
$$

A lucratividade do produtor é função de características, observadas ou não, do estabelecimento e do ambiente em que o estabelecimento está localizado. As características do estabelecimento são os insumos, a tecnologia e as habilidades pessoais do produtor. As características do ambiente incluem a qualidade do solo, o clima, os custos de transação que afetam o acesso aos mercados de insumos e produtos e o grau de concorrência dos mercados. A distribuição conjunta destes componentes determina a lucratividade do estabelecimento.

Dados os preços e a tecnologia, é natural supor que existe um limite máximo à lucratividade que pode ser descrito por uma função de fronteira. Os fatores observados que influenciam a lucratividade máxima são as variáveis explicativas dessa função, e os componentes não observados entram no resíduo. Seguindo a literatura de fronteira estocástica (COELLI, RAO e BATTESE, 1999; KUMBHAKAR e LOVELL, 2000), a existência de uma fronteira estocástica de lucratividade implica na assimetria da distribuição do erro. Esta condição permite decompor o erro em duas partes: um termo assimétrico (u) que será interpretado como a eficiência idiossincrática de cada produtor; e um termo aleatório que representa os demais determinantes ${ }^{15}$.

O logaritmo da lucratividade (L) é definido como função de $(\mathrm{x}, \mathrm{g}, \mathrm{d}, \mathrm{z}, \mathrm{h}, \mathrm{u})$ que constitui seis blocos de variáveis, as quais explicam as diferenças de lucratividade entre produtores: 1) a intensidade do uso de fatores de produção x (quantum de máquinas ${ }^{16}$, quantum de outras formas de capital ${ }^{17}$,

15 A crítica ao uso do modelo de fronteira estocástica está relacionada à capacidade de separar adequadamente ruído de ineficiência. Moreira e Fonseca (2005) realizam um exercício de simulação para comparar a capacidade dos modelos de fronteira estocástica e de análise envoltória de dados em estimar um termo de ineficiência previamente definido. Mostram que para amostras grandes e sob certas condições de assimetria este termo é adequadamente estimado com modelos de fronteira estocástica. Vale mencionar que estas duas condições são atendidas nos modelos estimados aqui.

16 Esta variável é a soma das quantidades de nove tipos de máquinas, ponderados pelos preços médios em São Paulo. Para mais detalhes sobre a construção de variáveis no modelo, ver Moreira, Helfand e Figueiredo (2007).

17 Esta variável é a agregação de: a) quantum de animais, igual a soma ponderada das quantidades de 17 tipos de animais em estoque ponderados pelos respectivos preços médios na região; e, b) quantum de lavoura permanente, igual à soma dos valores presentes descontados (a taxa de $6 \%$ ao ano) do fluxo futuro potencial das receitas geradas dos 13 tipos de lavouras, considerando-se os preços e as produtividades médias das regiões e as respectivas vidas produtivas médias de cada tipo de árvore. 
quantum de mão de obra familiar ${ }^{18}$ e gastos correntes ${ }^{19}$ ), todos medidos em logaritmo e normalizados com a área do estabelecimento; 2) as condições de clima e solo do município onde o produtor está localizado $(\mathrm{g})^{20}$; 3) o acesso a mercados (d) medido com o custo de transporte a São Paulo, a distância à capital do estado, a distância ao mar, e a distância esperada à sede do município, todos medidos em logaritmo ${ }^{21}$; 4) a disponibilidade de bens públicos e instituições (z) medida pela incidência de energia elétrica, assistência técnica, cooperativas e financiamento entre os estabelecimentos no município ${ }^{22}$; 5) uma família de variáveis indicadoras de classe de tamanho (h) que capta de forma flexível a relação entre a lucratividade e o tamanho do estabelecimento ${ }^{23}$; e 6) a eficiência do produtor (u), estimada no modelo de fronteira estocástica. Cada bloco contém o efeito da distribuição conjunta das variáveis do bloco e descreve uma fonte de explicação. Isto facilita a interpretação dos resultados porque as simulações serão feitas com blocos inteiros em vez de variáveis individuais.

A especificação de uma função translog nos fatores de produção (x), e linear nas outras variáveis para o modelo de fronteira estocástica de lucro, admite elasticidades de substituição variáveis entre os fatores de produção. A função translog é uma aproximação flexível de segunda ordem e normalmente é preferido às funções lineares, como a Cobb-Douglas, para modelos estimados com microdados. A imposição de retornos constantes de escala na tecnologia

18 Ver nota de rodapé 5 .

19 Os gastos correntes constituem os custos variáveis de produção. Incluem itens como a contratação de mão de obra, os serviços de máquinas terceirizados, as sementes, os combustíveis, os fertilizantes e os remédios.

20 As variáveis de $\mathrm{g}$ foram produzidas por Gerd Sparovek da Esalq/USP, a quem agradecemos. São nove variáveis que descrevem os solos, o clima e outros fatores naturais que restringem a aptidão de uma dada localidade para certas atividades agrícolas. São quatro índices relacionados à temperatura e precipitação, para lavouras anuais e perenes. Outros cinco índices são relacionados à fertilidade do solo, drenagem, resistência à erosão, potencial para mecanização e capacidade de enraizamento.

21 A distância foi calculada considerando-se o número de estabelecimentos por classe de tamanho em cada setor censitário e a distância do centroide do setor censitário à sede do município.

22 Para reduzir problemas de endogeneidade, os componentes da variável $\mathrm{z}$ têm as variáveis indicadoras de pertinência à classe de tamanho $(h)$ e município $(m)$ como instrumentos, resultando no valor médio desta variável por $(\mathrm{mh})$.

23 Foram consideradas sete classes de tamanho para as regiões Norte, Nordeste, Sul e Sudeste - até 5, 10, 20,50,150,500, mais de 500 hectares - e, para o Centro-Oeste - até $10,20,50,150,500,1.000$, mais de 1.000 hectares - devido à estrutura fundiária dessa região. 
Explicando as Diferenças de Pobreza entre Produtores Agrícolas no Brasil: simulações contrafactuais com o censo agropecuário 1995-96

garante que o tamanho do estabelecimento só afete os resultados através dos coeficientes das variáveis $(\mathrm{h})^{24}$.

Seja $r=(x, g, d, z, h)$, e $\left(f_{j}\right)$ o efeito conjunto das variáveis do bloco $j=1 \ldots 5$, então o modelo de fronteira estocástica do logaritmo da lucratividade é descrito com a equação (3) onde u é o termo da ineficiência idiossincrática e $\varepsilon$ é o erro aleatório:

$$
\ln \left(L_{i}\right)=\sum_{j=1}^{5} \alpha_{j} r_{j i}-u_{i}+\varepsilon_{i}, \quad u \sim N^{+}(0, \tau), \quad \varepsilon \sim N\left(0, \sigma^{2}\right)
$$

Definindo-se os termos $r_{6}=u, \alpha_{6}=-1 ; r_{7}=\varepsilon, \alpha_{7}=1 ; r_{8}=\ln (T), \alpha_{8}=1 ; r_{9}=$ $\ln (\mathrm{N}), \alpha_{9}=-1$, e a função $\mathrm{f}(\cdot)$ que calcula os fatores associados a cada bloco

$$
\mathrm{f}_{\mathrm{j}}\left(\mathrm{r}_{\mathrm{j}}\right)=\alpha_{\mathrm{j}} \mathrm{r}_{\mathrm{j}}, \mathrm{j}=1 \ldots 9
$$

o logaritmo da renda per capita do produtor é descrita por

$$
\ln (\pi)=\ln (L T / N)=\sum_{j=1}^{9} f_{j}\left(r_{j}\right)
$$

e a renda per capita é

$$
\pi=\exp \left(\sum_{j=1}^{9} f_{j}\left(r_{j}\right)\right)
$$

\subsection{Efeito das Variações das Distribuições}

Quando se estudam as fontes de diferenças entre dois grupos, como as diferenças nas rendas médias entre produtores no Nordeste e Sul, ou entre proprietários versus não proprietários numa dada região, uma abordagem comum é utilizar a decomposição Oaxaca-Blinder. Brevemente, explica-se aqui esta abordagem para realçar a diferença em relação ao que se fez neste artigo. Sejam dois grupos (A, B) em que a renda depende da quantidade de terra (T) e a tecnologia $(\alpha), \pi=\alpha \mathrm{T}$. A decomposição de Oaxaca-Blinder decompõe a diferença entre as rendas médias $\left(\pi_{A^{-}}-\pi_{B}\right)$ como: $\left(\pi_{A^{-}}-\pi_{B}\right)=\alpha_{A}\left(T_{A}-T_{B}\right)+T_{B}\left(\alpha_{A}-\alpha_{B}\right)$, onde a primeira parcela à direita da igualdade é o efeito devido às diferenças dos estoques médios de terras entre os dois grupos sobre a diferença das rendas médias; e a segunda é o efeito de elementos não observados (captados nos coeficientes) sobre a diferença das rendas médias. Portanto, a técnica de Oaxaca-Blinder analisa diferenças de rendas médias devido a diferenças médias nas variáveis observadas e não observadas.

24 Mais precisamente, a inclusão das variáveis (h) permite retornos não constantes de escala. Mas sem impor esta restrição na função translog, os retornos não constantes aparecem tanto na tecnologia como nas variáveis (h), e fica difícil calcular o impacto líquido de escala. 
Aqui, se propõe uma extensão da decomposição de Oaxaca-Blinder para explicar a diferença entre as distribuições de renda entre os dois grupos (produtores no Nordeste e Sul, proprietários e não proprietários etc.), decorrente da diferença entre as distribuições da terra (ou de qualquer outro determinante da renda). Por exemplo, as distribuições de renda e de terra entre os produtores do Nordeste e Sul são muito diferentes. Com este exercício, se avalia qual a contribuição da diferença entre a distribuição da terra do Nordeste e Sul para explicar a diferença entre a distribuição da renda nas duas regiões e, portanto, qual a contribuição da terra para explicar a diferença na incidência de pobreza nas duas regiões. A equação (5) e a diferença entre as distribuições da renda e das características dos produtores entre grupos são utilizadas para avaliar a importância de cada bloco de características (j) sobre a distribuição da renda.

$\mathrm{Na}$ literatura, existem duas abordagens comuns para a realização de exercícios contrafactuais deste tipo: a abordagem proposta por DiNardo, Fortin e Lemieux (1996) (DFL) e a proposta por Juhn, Murphy e Pierce (1993) (JMP). A abordagem de JMP já foi utilizada no Brasil por Barros, Carvalho e Franco (2006) e Azevedo e Foguel (2007). Escolhemos a segunda abordagem porque trata de forma não paramétrica o aspecto distributivo do problema e permite combinar o uso desta metodologia com o modelo de fronteira estocástica. Descreve-se a metodologia a seguir.

Seja a distribuição conjunta das variáveis do bloco j do grupo de produtores $A, r_{j} \sim \Psi_{j}^{A}$. O efeito do bloco de variáveis $\mathrm{j}$, que denomina-se fator $\mathrm{j}$, depende dos coeficientes $\alpha$ do bloco j estimado no grupo A. Então, a distribuição do efeito conjunto de variáveis deste bloco é:

$$
f_{j} \sim\left\{\alpha_{j}^{A} r_{j}^{A} \mid r_{j}^{A} \sim \Psi_{j}^{A}\right\}=\Phi_{j}^{A A}
$$

onde os sobrescritos AA identificam a tecnologia do grupo A $\left(\alpha_{j}^{A}\right)$ e a distribuição conjunta das variáveis do bloco (j) dos produtores do grupo A $\left(r_{j} \sim \Psi_{j}^{A}\right)$. Da mesma forma, a distribuição do mesmo fator $\mathrm{j}$ relativo ao grupo $\mathrm{B}$ de produtores seria $f_{j} \sim\left\{\alpha_{j}^{B} r_{j}^{B} \mid r_{j}^{B} \sim \Psi_{j}^{B}\right\}=\Phi_{j}^{B B}$. Como a equação 4 indica, a função $\mathrm{f}(\cdot)$ transforma as variáveis (r) em uma componente que representa o efeito conjunto das variáveis do bloco, ou seja, transforma elementos da distribuição conjunta de $\mathrm{r}$ em uma distribuição univariada que sumariza o efeito das variáveis deste bloco. As distribuições empíricas $\Phi_{j}^{A A}$ e $\Phi_{j}^{B B}$ são univariadas e os seus elementos podem ser ordenados segundo o seu valor para definir a função posto $p(q \mid \Phi)$ que associa ao percentil q o seu valor. Tambem pode-se definir a função inversa, $p^{-1}(q \mid \Phi)$, que associa a um dado valor da distribuição o seu percentil.

O exercício contrafactual avalia, para cada bloco (j) de variáveis, qual o efeito sobre a proporção de pobres no grupo A se estes recebessem a distribuição conjunta das variáveis do grupo $B$, mantendo constante a tecnologia $(\alpha)$ do grupo A, ou seja, se a distribuição $\Phi_{j}^{A A}$ fosse substituída pela distribuição $\Phi_{j}^{A B}=f_{j} \sim\left\{\alpha_{j}^{A} r_{j}^{B} \mid r_{j}^{B} \sim \Psi_{j}^{B}\right\}$. 
Seja um produtor do grupo A que tem a dotação de fatores do bloco $\mathrm{k}$ igual a x que é descrito com a distribuição $\Phi_{k}^{A A}$. Qual o preditor da dotação de fatores deste produtor quando a distribuição de dotações é substituída pela distribuição $\Phi_{k}^{A B}$ ? Admite-se que o preditor desta dotação na nova distribuição é tal que a posição relativa do produtor nas duas distribuições é a mesma, ou seja, ele permanece no mesmo percentil. Por exemplo, o produtor de menor (maior) dotação continua a ter a menor (maior) dotação na nova distribuição. Seja q o percentil do produtor que tem dotação $\mathrm{x}$ para o fator $\mathrm{k}$ na distribuição inicial, $q=p^{-1}\left(f_{k}=x \mid \Phi_{k}^{A A}\right)$, então o preditor da dotação $\mathrm{x}$ deste produtor na nova distribuição é $x^{*}=p\left(q \mid \Phi_{k}^{A B}\right)$. Ou seja, $x^{*}=p\left(p^{-1}\left(f_{k}=x \mid \Phi_{k}^{A A}\right) \mid \Phi_{k}^{A B}\right)$. O preditor para todos os valores do fator $\mathrm{f}_{\mathrm{k}}$ é dado por:

$$
f_{k}^{*}=p\left(p^{-1}\left(f_{k} \mid \Phi_{k}^{A A}\right) \mid \Phi_{k}^{A B}\right)
$$

A Figura 4 ilustra a transformação descrita na equação (7). O produtor que tem certa característica no nível 2 na distribuição acumulada da esquerda será substituído pelo produtor que tem 3 na distribuição da direita, porque os dois têm a mesma probabilidade acumulada de ocorrer nas duas distribuições. Como os produtores têm a mesma posição relativa para um dado fator, é imediato que a correlação de posto não é alterada. Esta construção, conhecida na literatura como "parada de Pen" (Pen, 1971), preserva a correlação entre o posto do fator porque preserva a posição relativa dos estabelecimentos antes e depois da substituição.

Figura 4. Equivalência em probabilidade

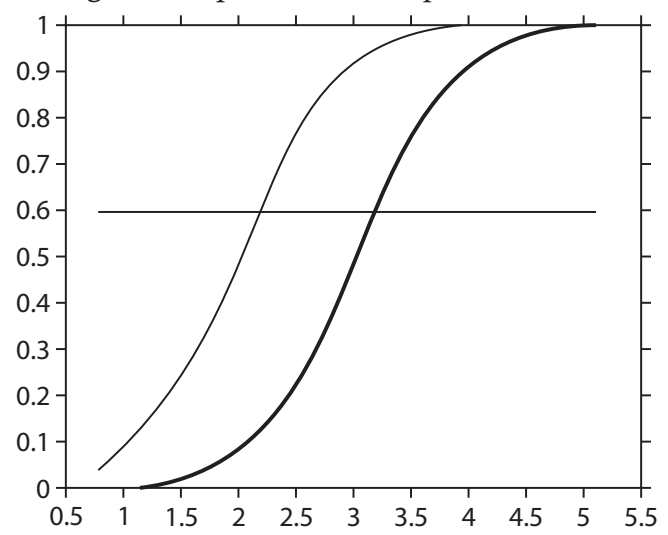

Fonte: Elaboração dos autores.

A distribuição da renda per capita no grupo A é $\pi \sim\left\{\exp \left(\sum_{j=1}^{9} f_{j}\right) \mid f_{j} \sim \Phi_{j}^{A A}\right\}=\Phi_{\pi}^{A A}$.

Então, definindo-se como pobre as pessoas que têm renda abaixo do valor $\pi^{\mathrm{P}}$, a proporção de pobres, ou a pobreza, no grupo A é: 


$$
P=p^{-1}\left(\pi^{P} \mid \Phi_{\pi}^{A A}\right)
$$

A renda per capita predita para os membros do grupo A quando recebem a distribuição do fator $f_{k}$ do grupo B é:

$$
\pi *=\exp \left(\sum_{j=1}^{9} f_{j}+f_{k}^{*}-f_{k}\right)=\pi \exp \left(f_{k}^{*}-f_{k}\right)
$$

Portanto, a distribuição da renda per capita predita para os membros do grupo A é:

$$
\pi^{*} \sim\left\{\pi \exp \left(f_{k}^{*}-f_{k}\right)\right\}=\Phi_{\pi}^{A, B, k}
$$

Em resumo, a distribuição da renda per capita simulada $\Phi_{\pi}^{A, B, k}$ foi gerada substituindo-se a distribuição do fator $f_{k}$, observada no grupo A, com a distribuição simulada de $f_{k}^{*}$. A simulação de $f_{k}^{*}$ é baseada na distribuição conjunta das variáveis $\Psi_{k}^{B}$ no grupo B e nos coeficientes de tecnologia $\alpha_{k}^{A}$ estimados para o grupo A. Dada a nova distribuição de renda, a proporção de pobres simulada é $P^{*}=p^{-1}\left(\pi^{P} \mid \Phi_{\pi}^{A, B, k}\right)$.

Este preditor da renda per capita supõe independência entre as distribuições dos fatores. Entretanto, se a distribuição da ineficiência depende da escala, por exemplo, ao substituirmos a distribuição da terra, deveríamos alterar conjuntamente a distribuição da ineficiência. Nesse sentido, o tamanho da propriedade é uma variável chave. É um fato estilizado na literatura de produtividade agrícola que o tamanho da propriedade é uma característica fundamental do produtor, e que as distribuições dos fatores determinantes da renda estão relacionadas com esta variável (ESWARAN e KOTWAL, 1985; BERRY e CLINE, 1979).

Para mitigar esta vulnerabilidade, o modelo foi especificado: 1) considerando-se o efeito conjunto das variáveis explicativas de cada bloco e, portanto, a dependência entre as variáveis de cada bloco foi considerada; e 2) considerando-se todas as distribuições, com exceção da distribuição da terra, condicionais ao tamanho do estabelecimento. Isto foi feito da seguinte forma: os estabelecimentos foram divididos em classes de tamanho h, e as distribuições dos fatores e da renda foram definidas de forma condicional a $\mathrm{h}: \Phi_{j h}^{A A}, \Phi_{j h}^{B B}, \Phi_{j h}^{A B}, \Phi_{\pi h}^{A A} \mathrm{e} \Phi_{\pi h}^{A, B, k}$ e o exercício de simulação foi realizado por classe de tamanho. Ou seja, a simulação foi feita substituindo-se os fatores entre as distribuições de produtores dos grupos A e B que são da mesma classe de tamanho. Com isto, foi controlado o eventual efeito do tamanho da propriedade sobre os fatores. Os resultados serão apresentados com o efeito do tamanho calculado de forma não condicional às classes e com o efeito dos demais componentes calculados de forma condicional. 
Explicando as Diferenças de Pobreza entre Produtores Agrícolas no Brasil: simulações contrafactuais com o censo agropecuário 1995-96

\section{Resultados}

Os microdados do Censo Agropecuário 1995-96 podem conter observações espúrias. Por exemplo, $8 \%$ dos produtores tinham renda negativa, e isso pode ser devido à quebra de safra, fase inicial de investimento, ou outros problemas de mensuração. Para reduzir o efeito destas observações, foi introduzido um filtro que excluiu estabelecimentos com produção ou terra nula, e o extremo superior da distribuição da razão entre cada uma das variáveis de interesse e a área do estabelecimento.

No total, foram excluídos da população cerca de $16 \%$ dos produtores. Devido à diversidade e à dimensão do meio agrícola brasileiro, a análise foi feita separadamente para cada uma das cinco macrorregióes: Norte (N), Nordeste (NE), Sudeste (SE), Sul (S), e Centro-Oeste (CO). A amostra considerou o total de 4.058.259 estabelecimentos, sendo: 360.908 no Norte; 1.994 .324 no Nordeste; 646.892 no Sudeste; 879.521 no Sul; e 176.614 no Centro-Oeste.

\subsection{Explicando a Diferença de Pobreza PA $_{\text {entre Regióes }}$}

As cinco regiões foram analisadas em dez pares, simulando, para cada par, a alteração das distribuições da região com mais pobreza. Por isso, em todos os resultados, o efeito da substituição conjunta de todos os componentes resulta em redução de pobreza. Nesta seção, se considera apenas o efeito da substituição dos componentes observados da renda do produtor: lucratividade, terra e mão de obra familiar.

A Tabela 2 mostra a redução na incidência de pobreza, que resulta da simulação que substitui a distribuição de cada um dos componentes da renda.

Tabela 2. Efeito sobre a pobreza ${ }_{\mathrm{RA}}$ da substituição de cada componente entre regiões

\begin{tabular}{lccccccccccc}
\hline \multirow{2}{*}{ Componentes } & \multicolumn{10}{c}{ Regiões comparadas } \\
\cline { 2 - 12 } & $N E \mid N$ & $N E \mid S E$ & $N E \mid S$ & $N E \mid C O$ & $N \mid S E$ & $N \mid S$ & $N \mid C O$ & $S E \mid S$ & $S E \mid C O$ & $C O \mid S$ \\
\hline Diferença de pobreza & $-0,28$ & $-0,44$ & $-0,54$ & $-0,41$ & $-0,16$ & $-0,26$ & $-0,23$ & $-0,10$ & $-0,07$ & $-0,03$ \\
Tamanho do estab. & $-0,31$ & $-0,42$ & $-0,36$ & $-0,51$ & $-0,10$ & $-0,03$ & $-0,19$ & 0,10 & $-0,06$ & 0,23 \\
Trabalho familiar & 0,00 & $-0,06$ & $-0,03$ & $-0,06$ & $-0,08$ & $-0,03$ & $-0,09$ & 0,04 & $-0,01$ & 0,04 \\
Lucratividade & $-0,22$ & $-0,16$ & $-0,28$ & $-0,17$ & 0,00 & $-0,15$ & $-0,01$ & $-0,14$ & 0,00 & $-0,11$ \\
\hline
\end{tabular}

Fonte: Dados da pesquisa.

A primeira linha refere-se à diferença da pobreza entre cada par de regiões. Isto seria o efeito de trocar todas as distribuições de forma não condicional. A segunda linha é a redução devido à substituição da distribuição da terra $(\mathrm{T})$, e as demais, ao efeito da substituição da distribuição do número de membros 
ocupados da família (N) e da lucratividade (L). Os componentes da renda são dependentes, e os efeitos de trabalho familiar e lucratividade são calculados condicionais à classe de tamanho (h). Portanto, a soma dos efeitos parciais é diferente do efeito conjunto apresentado na primeira linha.

Na coluna NE|S, a primeira linha indica que a substituição - de forma não condicional - da distribuição de todos os componentes da renda da região NE pela da região $S$ reduziria a incidência de pobreza em 54 pontos percentuais (pp). É notável que as diferenças da incidência de pobreza entre as regiões que não envolvem o N e NE são inferiores a 10 pp. Quando as comparações são com o N, as diferenças ultrapassam 20 pp, e quando envolvem o NE, as diferenças podem chegar à faixa de $50 \mathrm{pp}$.

A segunda linha da Tabela 2 mostra a importância do tamanho do estabelecimento. Em todos os casos, exceto para os pares SE/S e CO/S, a substituição da distribuição da terra reduz a incidência de pobreza, indicando que, na região com mais pobreza, a área dos estabelecimentos é menor para os produtores pobres. Esta redução responde por grande parte da diferença de incidência de pobreza entre as regiões. Por exemplo, se os produtores do NE tivessem a distribuição da terra dos produtores de qualquer outra região, a pobreza cairia entre 31 pp e 51 pp. Este resultado está de acordo com a visão de que os produtores pobres muitas vezes possuem áreas de tamanho insuficiente para saírem da pobreza.

A última linha da Tabela 2 mostra que a lucratividade é menor no NE e maior no $\mathrm{S}$ em comparação com as outras regiões. Se os estabelecimentos do NE tivessem a distribuição de lucratividade dos estabelecimentos de qualquer outra região, a incidência de pobreza cairia entre 16 pp e 28 pp, e se os estabelecimentos do N, SE ou CO tivessem a lucratividade dos produtores do S, isso levaria a uma redução da pobreza de 11 pp a 15 pp. As distribuições das demais regiões, quando substituídas entre si, não produzem alterações significativas. Como existe muita similaridade entre os conceitos de lucratividade e produtividade total dos fatores (PTF), os resultados sugerem alta PTF no $S$, e deficiências importantes de PTF no NE.

A terceira linha da Tabela 2 mostra que o efeito do número de membros ocupados da família é, em geral, menor do que o do tamanho ou o da lucratividade. $\mathrm{O}$ efeito do trabalho familiar só é grande nas comparações que envolvem o N e NE. Na maioria dos casos, o número de membros ocupados das famílias dos produtores das regiões mais pobres é maior do que a de seus correspondentes, exceto para os pares SE/S, CO/S.

\subsection{Explicando a Pobreza ${ }_{R A}$ dentro das Regióes}

A comparação entre as distribuições dos componentes da renda - T, L, e N dos produtores pobres e não pobres revela a importância de cada componente na determinação da pobreza (Tabela 3). Para cada região, foi estimado um 
Explicando as Diferenças de Pobreza entre Produtores Agrícolas no Brasil: simulações contrafactuais com o censo agropecuário 1995-96

modelo para a lucratividade do produtor, conforme a equação (3), o que também permite avaliar o efeito de todos os subcomponentes da lucratividade $\left\{\mathrm{f}_{1}, \ldots, \mathrm{f}_{5}, \mathrm{u}\right\}$.

Tabela 3. Efeito sobre a pobreza $a_{\mathrm{RA}}$ da substituição de cada componente: pobre e não pobre

\begin{tabular}{lccccc}
\hline \multirow{2}{*}{\multicolumn{1}{c}{ Componente }} & \multicolumn{5}{c}{ Regiões } \\
\cline { 2 - 6 } & $N$ & $N E$ & $S E$ & $S$ & $C O$ \\
\hline Incidência de PobrezaRA & 0,48 & 0,76 & 0,32 & 0,22 & 0,25 \\
Tamanho do estabelecimento & $-0,19$ & $-0,40$ & $-0,18$ & $-0,12$ & $-0,17$ \\
Trabalho familiar & $-0,11$ & $-0,12$ & $-0,08$ & $-0,06$ & $-0,07$ \\
Lucratividade - total & $-0,34$ & $-0,44$ & $-0,25$ & $-0,18$ & $-0,19$ \\
Lucratividade - ineficiência & $-0,15$ & $-0,09$ & $-0,13$ & $-0,10$ & $-0,13$ \\
Lucratividade - Fatores de Produção & $-0,13$ & $-0,13$ & $-0,10$ & $-0,04$ & $-0,06$ \\
\hline
\end{tabular}

Fonte: Dados da pesquisa.

A primeira linha da Tabela 3 mostra a incidência de pobreza pa $_{\text {en cada }}$ região, e as outras linhas mostram - um por um - o efeito do trocar a distribuição indicada entre os produtores pobres e não pobres. Da mesma forma que foi feita na Tabela 2, a importância da distribuição da terra foi avaliada de forma não condicional, e a importância dos outros componentes foi avaliada de forma condicional. Por parcimônia, nas tabelas que se seguem foram omitidas as linhas dos componentes que têm efeito inferior a 5 pp em todas as regiões.

Da mesma forma que diferenças de tamanho tiveram um papel fundamental na explicação de diferenças de pobreza entre regiões, a Tabela 3 mostra que estas diferenças também são importantes dentro das regiões. Se os produtores pobres tivessem a distribuição de terra dos produtores não pobres, a pobreza seria reduzida entre 12 pp no S e 40 pp no NE. Mas, além de ter menos terra, o produtor pobre também é menos lucrativo do que o produtor não pobre. A troca da distribuição da lucratividade reduziria a pobreza entre 18 pp no S e 44 pp no NE. De fato, o efeito da distribuição da lucratividade é maior que o efeito do tamanho em todas as regiões, mas a diferença não é tão grande no NE e CO.

Os valores negativos na terceira linha da Tabela 3 indicam que os produtores pobres têm mais membros da família ocupados na produção do que os não pobres, e a troca da distribuição de mão de obra familiar dos produtores pobres pela dos não pobres reduziria a pobreza em até 12 pp no NE. Embora as diferenças no trabalho familiar representem um papel pequeno na explicação das diferenças entre as regiões conforme a Tabela 2 , elas se mostraram muito mais importantes na explicação entre pobres e não pobres dentro das regiões. Este efeito, como proporção do efeito de tamanho, varia de $30 \%$ no NE a $58 \%$ no N.

As últimas duas linhas da Tabela 3 ajudam a esclarecer porque os produtores pobres são menos lucrativos do que os não pobres. O produtor pobre é menos 
lucrativo porque utiliza os fatores de produção de forma menos intensiva ${ }^{25}$, e também porque os utiliza de forma menos "eficiente". A "ineficiência" implica que está mais longe da fronteira de lucro. Não sabemos se produtores pobres são ineficientes por razões intrínsecas, como habilidade, ou devido a variáveis não observadas, como restrições de crédito, falhas de mercado, idade da tecnologia etc. As magnitudes destes dois componentes são da mesma ordem de grandeza do efeito do trabalho familiar.

As variáveis municipais $(\mathrm{g}, \mathrm{d}, \mathrm{z})$ explicam menos do que $5 \mathrm{pp}$ em todas as regiões. $\mathrm{O}$ fato de clima, solo, distância e infraestrutura não terem impacto grande na lucratividade sugere que as diferenças nas distribuições dessas variáveis entre pobres e não pobres não é determinante.

\subsection{Clivagem dos Produtores e Pobreza PA}

Características variadas do produtor poderiam distinguir a condição de pobreza. Para avaliar isto, selecionamos uma lista de clivagens frequentemente mencionadas na literatura de economia agrícola e desenvolvimento econômico. Os atributos considerados foram: ser proprietário do estabelecimento (prop/ ñprop); ser um estabelecimento familiar definido como não contratar mão de obra (fam/ñfam); ter intensidade de gasto corrente maior do que a mediana da região (int/ñint); e, finalmente, ter máquina (maq/ñmaq). Explica-se a razão dessas escolhas a seguir.

Um determinante importante do comportamento do produtor está relacionado com o direito de propriedade do estabelecimento. O proprietário em tese tem mais incentivo para trabalhar, mais acesso a linhas de crédito e mais incentivo para investir no estabelecimento, o que poderia afetar a produtividade e a sua renda.

Um dos fatos estilizados da literatura internacional de desenvolvimento econômico é que o produtor familiar é mais produtivo do que o não familiar e deveria ser incentivado. O produtor do tipo família foi identificado aqui pela não contratação de mão de obra, ou seja, funciona exclusivamente com mão de obra da família. Em 1995-96, no Brasil, cerca de 70\% dos produtores foram deste tipo.

$\mathrm{O}$ acesso à tecnologia revela o grau de conhecimento, capacidade gerencial e restrições a crédito a que o produtor está sujeito. Foram consideradas duas medidas de nível tecnológico: 1) grau de intensidade de gastos correntes, e 2) a condição de ter máquina. Os gastos correntes referem-se à compra de sementes, defensivos, medicamentos para animais, combustíveis, contratação de mão de obra e outras coisas. São itens que, na sua maioria, referem-se à compra ou à utilização implícita de tecnologia. Com este argumento, interpreta-se a intensidade de gastos correntes como indicação do nível tecnológico do

25 Os fatores (x) estão definidos por hectare. Por isso, a interpretação é de intensidade. 
412 - Explicando as Diferenças de Pobreza entre Produtores Agrícolas no Brasil: simulações contrafactuais com o censo agropecuário 1995-96

produtor. Para distinguir um tipo do outro, considera-se, para cada região, a mediana da distribuição desta variável. Portanto, cada um dos tipos (alto e baixo nível tecnológico) tem $50 \%$ dos produtores. Finalmente, considera-se a condição de ter máquina como outro indício do nível tecnológico do produtor.

A Tabela 4 mostra a diferença da incidência de pobreza em cada região para cada um dos tipos de produtor. A tabela mostra que a maioria dos atributos tem capacidade de identificar a pobreza em todas as regióes. Os produtores do tipo família, por exemplo, têm entre $15 \mathrm{pp}$ e $36 \mathrm{pp}$ mais pobreza do que os do tipo não família. Os que não têm máquina têm entre 18 pp e 47 pp mais pobreza do que aqueles que têm. Apenas o tipo ser proprietário (prop) para as regiões $\mathrm{N}$ e SE, e ser intensivo (int), para as regiões $\mathrm{N}$ e $\mathrm{NE}$, revelaram diferenças de incidência de pobreza igual ou inferior a $5 \mathrm{pp}$. Para todos os tipos foi realizado o exercício contrafactual, isolando a contribuição dos componentes observados da renda, e sempre considerando-se o tipo que tem maior incidência de pobreza, como o de referência.

Tabela 4. Diferença da pobreza ${ }_{\text {RA }}$ por tipo de produtor e região

\begin{tabular}{lccccc}
\hline \multirow{2}{*}{ Tipo de produtor* } & \multicolumn{5}{c}{ Regiões } \\
\cline { 2 - 6 } & $N$ & $N E$ & $S E$ & $S$ & $C O$ \\
\hline$P_{\text {prop }}-P_{\text {ñprop }}$ & $-0,05$ & $-0,16$ & $-0,01$ & $-0,09$ & $-0,12$ \\
$P_{\text {ñfam }}-P_{\text {fam }}$ & $-0,22$ & $-0,36$ & $-0,26$ & $-0,15$ & $-0,25$ \\
$P_{\text {int }}-P_{\text {ñint }}$ & $-0,05$ & $-0,05$ & $-0,22$ & $-0,21$ & $-0,09$ \\
$P_{\text {maq }}-P_{\text {ñmaq }}$ & $-0,30$ & $-0,47$ & $-0,28$ & $-0,18$ & $-0,24$ \\
\hline
\end{tabular}

* Incidência de pobreza P para a condição de ser: proprietário (prop) ou não (ñprop); familiar (fam) ou não (ñfam); intensivo (int) ou não (ñint); e com máquina (maq) ou não (ñmaq).

Fonte: Dados da pesquisa.

Na Tabela 5, a variação na incidência de pobreza devido à condição de ser proprietário é relativamente pequena, embora os proprietários tenham menos pobreza em todas as regióes. A área do estabelecimento é a principal fonte de explicação desta variação. Chama a atenção que - condicional ao tamanho nem o trabalho familiar nem a lucratividade contribuem de forma significativa para explicar a diferença de pobreza entre proprietários e não proprietários dentro de cada região (exceto no caso de lucratividade no SE).

Ser um estabelecimento de tipo família - definido pela não contratação de mão de obra - distingue a probabilidade de ser pobre muito mais do que ser proprietário (Tabela 6). Mas, nos dois casos, a principal fonte é a diferença da distribuição da terra. Os produtores não familiares têm menos membros ocupados no estabelecimento, o que aumenta a renda per capita dos membros ocupados da família. O efeito da diferença de lucratividade e de seus componentes é pequeno para a maioria dos casos. 
Tabela 5. Efeito sobre a pobreza $\mathrm{RA}_{\mathrm{R}}$ da substituição de cada componente: proprietário e não proprietário

\begin{tabular}{lccccc}
\hline \multirow{2}{*}{\multicolumn{1}{c}{ Componente }} & Regiões \\
\cline { 2 - 6 } & $N$ & $N E$ & $S E$ & $S$ & $C O$ \\
\hline Incidência de Pobreza $_{\mathrm{RA}}$ & $-0,05$ & $-0,16$ & $-0,01$ & $-0,09$ & $-0,12$ \\
Tamanho do estabelecimento & $-0,30$ & $-0,41$ & $-0,13$ & $-0,10$ & $-0,22$ \\
Trabalho familiar & 0,02 & $-0,02$ & 0,02 & 0,02 & 0,00 \\
Lucratividade & 0,03 & $-0,03$ & 0,09 & $-0,01$ & 0,00 \\
\hline
\end{tabular}

Fonte: Dados da pesquisa.

Tabela 6. Efeito sobre a pobreza $\mathrm{RA}_{\mathrm{A}}$ da substituição de cada componente: não família e família

\begin{tabular}{lccccc}
\hline \multirow{2}{*}{\multicolumn{1}{c}{ Componente }} & Regiões \\
\cline { 2 - 6 } & $N$ & $N E$ & $S E$ & $S$ & $C O$ \\
\hline Incidência de Pobreza $_{\text {RA }}$ & $-0,22$ & $-0,36$ & $-0,26$ & $-0,15$ & $-0,25$ \\
Tamanho do estabelecimento & $-0,33$ & $-0,39$ & $-0,25$ & $-0,13$ & $-0,27$ \\
Trabalho familiar & $-0,07$ & $-0,08$ & $-0,08$ & $-0,03$ & $-0,08$ \\
Lucratividade - total & $-0,02$ & $-0,11$ & $-0,05$ & $-0,02$ & $-0,04$ \\
Lucratividade - fatores de produção & $-0,07$ & $-0,08$ & $-0,07$ & 0,00 & $-0,03$ \\
\hline
\end{tabular}

Fonte: Dados da pesquisa.

A condição de produtor intensivo não distingue bem a incidência de pobreza no N e NE (Tabela 7). Nessas regiões, o produtor não intensivo somente tem 5 pp mais pobreza do que o intensivo. Em todos os casos, o produtor não intensivo tem mais área do que o intensivo, e se recebesse a distribuição de terra do intensivo, a pobreza aumentaria. Em todos os casos, no entanto, o não intensivo também é menos lucrativo. Se os produtores não intensivos tivessem a distribuição de lucratividade dos intensivos, a pobreza cairia entre 13 e 22 pp dependendo da região. A diferença de lucratividade é basicamente devido à diferença de intensidade de fatores. De fato, para o SE e $S$, as duas regiões onde se têm as maiores diferenças nas taxas de pobreza entre intensivo e não intensivo, o efeito das diferenças na área é muito pequeno, e o efeito das diferenças na lucratividade e no uso de insumos (x) é grande.

Chama a atenção que o efeito de bens públicos e instituições (z) só é relevante no S, e o componente de ineficiência (u) não é relevante. É interessante que a ineficiência não é uma fonte de pobreza neste caso. Implica que os produtores intensivos não estão mais perto da fronteira de lucro do que os produtores não intensivos. Isto sugere que diferenças em características intrínsecas (e não observadas) entre produtores intensivos e não intensivos não são uma fonte das diferenças de pobreza. 
414 - Explicando as Diferenças de Pobreza entre Produtores Agrícolas no Brasil: simulações contrafactuais com o censo agropecuário 1995-96

Tabela 7. Efeito sobre a pobreza ${ }_{R A}$ da substituição de cada componente: intensivo e não intensivo

\begin{tabular}{lccccc}
\hline \multirow{2}{*}{\multicolumn{1}{c}{ Componente }} & \multicolumn{5}{c}{ Regiões } \\
\cline { 2 - 6 } & $N$ & $N E$ & $S E$ & $S$ & $C O$ \\
\hline Incidência de Pobreza ${ }_{\text {RA }}$ & $-0,05$ & $-0,05$ & $-0,22$ & $-0,21$ & $-0,09$ \\
Tamanho do estabelecimento & 0,33 & 0,13 & 0,03 & 0,05 & 0,15 \\
Trabalho familiar & $-0,01$ & $-0,04$ & $-0,03$ & 0,03 & $-0,02$ \\
Lucratividade - total & $-0,18$ & $-0,22$ & $-0,21$ & $-0,22$ & $-0,13$ \\
Lucratividade - fatores de produção & $-0,17$ & $-0,14$ & $-0,18$ & $-0,09$ & $-0,07$ \\
Lucratividade - bens públicos e instituições & $-0,01$ & $-0,01$ & $-0,02$ & $-0,07$ & $-0,04$ \\
\hline
\end{tabular}

Fonte: Dados da pesquisa.

A relação entre a incidência de pobreza e a condição de não ter máquina é expressiva para todas as regiões, assim como o efeito da área e da lucratividade (Tabela 8).

Tabela 8. Efeito sobre a pobreza ${ }_{R A}$ da substituição de cada componente: máquina e não máquina

\begin{tabular}{lccccc}
\hline \multirow{2}{*}{\multicolumn{1}{c}{ Componente }} & $N$ & $N E$ & $S E$ & $S$ & $C O$ \\
\cline { 2 - 6 } & $-0,30$ & $-0,47$ & $-0,28$ & $-0,18$ & $-0,24$ \\
\hline Incidência de Pobreza ${ }_{\text {RA }}$ & $-0,41$ & $-0,59$ & $-0,25$ & $-0,16$ & $-0,27$ \\
Tamanho do estabelecimento & $-0,02$ & $-0,01$ & 0,00 & 0,03 & 0,00 \\
Trabalho familiar & $-0,10$ & $-0,14$ & $-0,16$ & $-0,08$ & $-0,10$ \\
Lucratividade - total & $-0,17$ & $-0,17$ & $-0,16$ & $-0,08$ & $-0,09$ \\
\hline Lucratividade - fatores de produção & & & & & \\
\hline
\end{tabular}

Fonte: Dados da pesquisa.

Neste caso, a intensidade do uso dos fatores (x) é uma fonte importante de diferença da lucratividade e, portanto, de diferença da renda, mas chama a atenção, de novo, que a ineficiência não é uma fonte de diferença de renda entre os dois tipos de produtores.

\section{Conclusão}

Para se avaliar o efeito de variáveis explicativas sobre a diferença de pobreza entre dois grupos, como proprietáriose não proprietários ou produtoresfamiliares e não familiares, foi utilizada a metodologia de simulações contrafactuais de Juhn, Murphy e Pierce (1993), que avalia o efeito da diferença entre distribuições. 
Com base nas simulações, e dentro do universo de produtores agrícolas no Brasil, o artigo procurou determinar os fatores que explicam as diferenças de pobreza entre as macrorregiões brasileiras, determinam a pobreza dentro de cada região, e explicam as diferenças na pobreza entre grupos distintos em uma dada região. Em todos os casos enfatizou-se a relação entre pobreza, o tamanho do estabelecimento e a produtividade.

Uma das conclusões centrais do artigo é que nem a terra nem a produtividade devem, por si mesmas, solucionar o problema da pobreza. Esta conclusão foi evidente na análise descritiva na seção 3 e confirmada nas simulações contrafactuais da seção 5. No Nordeste, por exemplo, em torno de dois terços dos estabelecimentos têm menos de 10 hectares. No nível de produtividade observada para os estabelecimentos no 5으 décimo de produtividade, um aumento do tamanho do estabelecimento de 5-10 hectares para 20-50 hectares não reduziria a incidência de pobreza - calculada apenas com a renda agrícola - para abaixo de $70 \%$.

De forma similar, mesmo que os estabelecimentos com 5-10 hectares pudessem ser tão produtivos quanto aqueles no 9o décimo de produtividade, $60 \%$ ainda seriam classificados como pobres. Desta forma, existe pouca dúvida de que para os produtores pobres, mais terra e maiores níveis de produtividade precisam estar associados de modo que a agricultura contribua para a redução da pobreza rural. Pesquisas futuras deverão abordar as razões benefício/custo destas duas estratégias, e as políticas mais eficazes para o aumento da produtividade.

A análise da pobreza entre as macrorregiões revelou que as diferenças de tamanho dos estabelecimentos entre regiões é um fator chave; a lucratividade no Nordeste é muito inferior, e no Sul, muito superior do que nas outras regiões; e a quantidade de mão de obra familiar ocupada no estabelecimento contribui para aumentar a pobreza, mas não de forma significativa na maioria dos casos. Este último resultado sugere que o excesso de população que gera uma produtividade marginal do trabalho muito baixa (LEWIS, 1954) não é a explicação mais importante para os altos níveis de pobreza na agricultura do Norte e Nordeste do Brasil.

A comparação entre tipos de produtor - proprietário/não proprietário, família/não família, intensivo/não intensivo, máquina/não máquina - mostrou que para explicar a diferença da incidência de pobreza: 1) o tamanho do estabelecimento é uma fonte de explicação em todos os casos; 2) a quantidade de mão de obra familiar é marginalmente significativa; 3) a lucratividade é importante, embora com menor relevância para as dicotomias família/não família e proprietário/não proprietário; 4) a disponibilidade de bens públicos e instituições só se mostrou importante para a dicotomia intensivo/não intensivo, embora com pouca relevância; 5) o efeito das condições municipais de clima, solo e distância foi pequeno; e 6) a ineficiência é uma fonte da diferença de pobreza apenas para a dicotomia pobre/não pobre. 
416 - Explicando as Diferenças de Pobreza entre Produtores Agrícolas no Brasil: simulações contrafactuais com o censo agropecuário 1995-96

O componente da ineficiência refere-se às variáveis não observadas e idiossincráticas do produtor. É interessante que esta quantidade não discriminou a condição de pobreza das dicotomias consideradas, exceto no caso pobre/não pobre. Isto significa que os produtores dos dois grupos destas dicotomias proprietário ou não, família ou não, intensivo ou não - não se distinguem devido a este componente não observado, ou seja, a menos de ruído, a diferença de pobreza é explicada pelos demais componentes observados. Chama a atenção que as variáveis não observadas - sejam habilidade, idade da tecnologia, restrições etc. - se mostrem um dos componentes mais importantes para distinguir a condição de produtor pobre. Uma pesquisa futura deve procurar compreender por que alguns produtores são mais eficientes que outros. A resposta a esta preocupação tem importantes implicações na formulação de políticas de redução de pobreza entre produtores agrícolas.

\section{Referências Bibliográficas}

AZEVEDO, J.P.; FOGUEL, M.N. Uma decomposição da desigualdade de rendimentos do trabalho no Brasil, 1995-2005. In: BARROS, R.P.; FOGUEL, M.N.; ULYSSEA, G. Desigualdade de renda no Brasil: uma análise da queda recente. Brasília: Ipea, 2007. Vol.2. 2007. p. 343-364.

BARROS, R.P.; CARVALHO, M.; FRANCO, S. Pobreza Rural em Honduras: magnitudy determinantes. Tegucigalpa, Honduras: Alin Editora/IPEA/PNUD. 2006. Disponível em: http://www.ipea.gov.br/sites/000/2/livros/Livro_PobrezaRural.pdf.

BERRY, R.A.; CLINE, W. Agrarian Structure and Productivity in Developing Countries, Baltimore: Johns Hopkins University Press. 1979.

BLINDER, A.S. Wage discrimination: reduced form and structural estimates. Journal of Human Resources, Vol. 8, 1973. p.436-455.

BRESCIANI, F.; VALDÉS, A. (eds.). Beyond Food Production: The Role of Agriculture in Poverty Reduction, Northampton, MA: FAO e Edward Elgar Publishing Inc., 2007.

BUAINAIN, A. M.; NEDER, H. D. Crisis y pobreza rural en América Latina: el caso de Brasil. Documento de Trabajo $\mathrm{N}^{\circ}$ 38. Programa Dinámicas Territoriales Rurales. Rimisp, Santiago, Chile. 2009.

CAMPANHOLA, C.; GRAZIANO DA SILVA, J. O Novo Rural Brasileiro: Uma Análise Nacional e Regional, São Paulo: Embrapa, 2000.

COELLI, T.; RAO, D.S.P.; BATTESE, G.E. An Introduction to Efficiency and Productivity Analysis, Norwell: Kluwer Academic Publishers, 1999.

CORRÊA, A.M.C.J. Distribuição de Renda e Pobreza na Agricultura Brasileira (19811990). Piracicaba: Editora UNIMEP, 1998. 
DE JANVRY, A.; SADOULET, E. Rural Poverty in Latin America: Determinants and Exit Paths. Food Policy, Vol. 25, 2000. p. 389-409.

DINARDO, J.; FORTIN, N.M; LEMIEUX, T. Labor market institutions and the distribution of wages, 1973-1992: A semiparametric approach. Econometrica, Vol. 64, no. 5, Set. 1996. p.1001-1044.

ESWARAN, M.; KOTWAL, A. A Theory of Contractual Structure in Agriculture, American Economic Review, Vol. 75, no. 3, 1985. p.352-67.

FERREIRA, F.H.G.; LEITE, P.G.; RAVALLION, M. Poverty reduction without economic growth: Explaining Brazil's poverty dynamics, 1985-2004, Journal of Development Economics, Vol. 93, pp. 20-36, 2010.

FERREIRA, F.H.G.; LANJOUW, P. Rural Nonfarm Activities and Poverty in the Brazilian Northeast, World Development, Vol. 29, N.3, pp. 509-28, 2001.

FIGUEIREDO, F.M.R.; HELFAND, S.M.; LEVINE, E. Income versus Consumption Measures of Rural Poverty and Inequality in Brazil, Seminário Pobreza Rural no Brasil: O Papel as Políticas Públicas, Brasília, DF, 17-18 de Abril de 2007.

FINAN, F:; SADOULET, E.; DE JANVRY, A. Measuring the poverty reduction potential of land in rural Mexico. Journal of Development Economics, Vol. 77, 2005. p.27-51.

GASQUES, J.G.; CONCEIÇÃO, J.C.P.R. Transformações Estruturais da Agricultura e Produtividade Total dos Fatores. Texto Para Discussão n. 768. Brasília, novembro de 2000.

GUANZIROLI, C.; ROMEIRO, A.; BUAINAIN, A.M.; DI SABBATO, A.; BITTENCOURT, G. Agricultura Familiar e Reforma Agrária no Século XXI, Rio de Janeiro: Editora Garamond Ltda., 2001.

HELFAND, S.M. What can be learned from the Agricultural Censuses about rural poverty in Brazil? Anais do XLII Congresso da Sociedade Brasileira de Economia e Sociologia Rural, CD-ROM, Cuiabá, Mato Grosso, 25 a 28 de Julho, 2004, Brasília: SOBER, 2004.

HELFAND, S.M.; LEVINE, E.S. The Impact of Policy Reforms on Rural Poverty in Brazil: Evidence from Three States in the 1990s. In: BOYCE, J.; CULLENBERG, S.; PATTANAIK, P.; POLLIN, R. (eds.). Human Development in the Era of Globalization, Northampton: Edward Elgar, 2006. p.105-25.

HELFAND, S.M.; ROCHA, R.; VINHAIS, H.E.F. Pobreza e desigualdade de renda no Brasil rural: uma análise da queda recente. Pesquisa e Planejamento Econômico, v.39, n.1, abr. 2009. p.59-80.

HOFFMANN, R. Elasticidade da pobreza em relação à renda média e à desigualdade no Brasil e nas unidades da federação. Revista Economia, Jul. 2005. 
418 - Explicando as Diferenças de Pobreza entre Produtores Agrícolas no Brasil: simulações contrafactuais com o censo agropecuário 1995-96

INSTITUTO BRASILEIRO DE GEOGRAFIA E ESTATÍSTICA (IBGE), Censo Agropecuário 1995-96. Rio de Janeiro: IBGE, 1998. , Censo Demográfico 1991. Rio de Janeiro: IBGE, 1992. , Censo Demográfico 2000. Rio de Janeiro: IBGE, 2001.

JUHN, C.; MURPHY, K.; PIERCE, B. Wage inequality and the rise in returns to skill. Journal of Political Economy, vol. 101, no. 3, 1993. p. 410-442.

KAGEYAMA, A.; HOFFMANN, R. Pobreza no Brasil: uma perspectiva multidimensional. Economia e Sociedade, v. 15, n. 1, v. 26, p. 79-112, 2006.

KUMBHAKAR, S.C.; LOVELL, C.A.K. Stochastic Frontier Analysis, Cambridge: Cambridge University Press, 2000.

LEWIS, W.A. Economic development with unlimited supplies of labor. Manchester School of Economic and Social Studies, Vol. 22, 1954. p. 139-191.

MOREIRA, A.R.B.; HELFAND, S.M.; FIGUEIREDO, A.M.R. Explicando as Diferenças na Produtividade Agrícola no Brasil. Rio de janeiro: IPEA. Texto para Discussão N. 1254. Jan. 2007. 34p. 2007.

MOREIRA, A.R.B.; FONSECA, T.C.R. Comparando Medidas de Produtividade: DEA, fronteira de produção estocástica. Rio de Janeiro: IPEA, 2005. (Texto para Discussão no 1069).

NEY, M.C.; HOFFMANN, R. Educação, concentração fundiária e desigualdade de rendimentos no meio rural brasileiro. Revista de Economia e Sociologia Rural, v. 47, n. 01, p.147-182. 2009.

OAXACA, R. Male-female wage differentials in urban labor markets. International Economic Review, Vol. 14, 1973. p.693-708.

PEN, J. Income Distribution. London Allen Lane, 1971.

PNUD, IPEA, FUNDAÇÃO JOÃO PINHEIRO. Atlas do desenvolvimento humano no Brasil. Rio de Janeiro: PNUD,IPEA, Fundação João Pinheiro, 2003.

ROCHA, S. Pobreza: Evolução Recente e as "Portas de Saída" para os Pobres. Fórum especial a grande revolução - integração de desenvolvimento e democracia. 27 de setembro de 2007. São Paulo: INAE, 2007.

SILVEIRA, F. G.; CARVALHO, A. X. Y.; AZZONI, C. R.; CAMPOLINA, B.; IBARRA, A. Dimensão, magnitude e localização das populações pobres no Brasil. Texto para discussão, n. 1.278, Rio de Janeiro: IPEA, 2007.

WORLD BANK. Brazil: Measuring Poverty Using Household Consumption, Document of the World Bank, Report No: 36358-BR. 2006.

WORLD BANK. Agriculture for development, The World Development Report 2008, New York: The World Bank, 2008. 